\title{
Los pasiegos. La analogía salvaje y lo salvaje de la analogía
}

\author{
Jaime de la Calle Valverde \\ Dpto. Sociología I UNED \\ jdlcalle@poli.uned.es
}

Recibido: 10.10 .2007

Aceptado: 19.12.2007

\section{BUSCADORES DE ANALOGÍAS}

Hubo un tiempo en el que el encuentro del antropólogo con las sociedades a las que estudiaba ponía frente a frente dos formas de hacer y pensar el mundo diferentes que representaban, por un lado, al pensamiento racional y, por otro, al pensamiento mitopoiético. Fue así, por lo menos, mientras existieron lo que los antropólogos llamaron «sociedades primitivas» y, también, mientras esas sociedades primitivas mantuvieron aquellas formas de pensar que Lévi-Strauss identificó en «El pensamiento salvaje». Pensamiento, diría, «que no es, para nosotros, el pensamiento de los salvajes, ni el de una humanidad primitiva o arcaica, sino el pensamiento en estado salvaje, distinto del pensamiento cultivado o domesticado con vistas a obtener un rendimiento» (2005: 317). También fue así mientras existieron las «sociedades tradicionales» (nuestros primitivos), cuyas formas de pensar incluían también discursos mitopoiéticos.

El discurso indígena mitopoiético, arropado en cientos de analogías (metáforas y otros recursos intelectuales), de código cerrado y de carácter cósmico, une todo con todo mediante un estilo decorativo, en ocasiones poético. En el pensamiento analógico las partes que se asocian en paralelo por presentar similitudes u homologías pertenecen a universos sensibles diferentes; para explicar unos hechos se recurre a otros similares aunque de ámbitos distintos; dos contextos que, en un principio resultan diferentes, aparecen análogos como resultado de la proyección de uno sobre otro. Es de código cerrado porque se requiere conocer los significados, valores y sentidos locales del complejo analógico para poder comprender su alcance. Pero, aunque de código cerrado, el pensamiento analógico es abierto al buscar relaciones hacia afuera. Por ello es expansivo. Su uso se asocia a sociedades estables y cerradas donde no es necesario argumentar o cuestionar nada. 
El discurso racional, trenzado con multitud de argumentos, es de código abierto, abierto a la comunicación y al cambio, desarrollándose a través de una concatenación de reflexiones que resulta persuasiva. En el pensamiento racional las partes que se asocian entre sí por presentar relaciones de causa-efecto pertenecen al mismo orden; dos o más partes de un mismo orden sensible se encadenan unas a otras mediante un sistema lógico; para explicar unos actos se recurre a los anteriores y así sucesivamente. El discurso racional compartimenta, «raciona», relacionando todo con todo en un micromundo de reflexión, en el que encadena una parte con otra. Es de código abierto porque el significado pretende ser comprensible independientemente de las culturas, de los grupos sociales o del género. Aunque es de código abierto, el pensamiento racional es cerrado en el sentido que busca relaciones hacia adentro. El pensamiento racional es contractivo ${ }^{1}$.

En palabras de Lévi-Strauss, el indígena «es un modo de pensar que parte del principio de que si no se comprende todo no se puede explicar nada, lo cual es absolutamente contradictorio con la manera de proceder del pensamiento científico, que consiste en avanzar etapa por etapa, intentando dar explicaciones para un determinado número de fenómenos y progresar, enseguida, hacia otro tipo de fenómenos, y así sucesivamente $»^{2}$.

En buena proporción, los antropólogos han sido y son «buscadores de analogías» (analogía como una de las formas discursivas que tiene de mostrarse el pensamiento que llamamos mitopoiético).

Unos buscan analogías con el objetivo de comprenderlas al ubicarlas en universos de sentido culturales. Especialmente entre los antropólogos simbólicos, interpretativos o los antropólogos levistraussianos se ha favorecido la «comprensión» del pensamiento indígena ${ }^{3}$. Las analogías — metáforas y otras mane-

${ }^{1}$ Douglas ha llevado ha cabo una interpretación basada en estos términos — de donde están inspirados- del libro del Levítico, escrito, según afirma, en un lenguaje analógico a diferencia del Deuteronomio escrito en un lenguaje racional y argumental (2006, especialmente pp. 35-62).

2 Y sigue: «Como ya dijo Descartes, el pensamiento científico divide la dificultad en tantas partes como sea necesario para resolverla» (Lévi-Strauss, op. cit., 1990: 38).

${ }^{3}$ La ciencia, según Lévi-Strauss, «es reduccionista cuando descubre que es posible reducir fenómenos que en un determinado nivel son muy complejos a fenómenos más simples en otros niveles. Por ejemplo, hay muchas cosas en la vida que pueden ser reducidas a procesos físico-químicos que las explican parcialmente aunque no en forma total. Y cuando nos enfrentamos con fenómenos tan complejos que no permiten su reducción a fenómenos de orden inferior, sólo podremos abordarlos estudiando sus relaciones internas, esto es intentando comprender qué tipo de sistema original forman en conjunto. $\mathrm{Y}$ es esto, precisamente, lo que intentamos hacer en lingüística, en la antropología y en muchos otros campos (op. cit., p. 28).

4 «Al estudiar estos pueblos, el antropólogo desea hacer inteligibles, para él y sus lectores, tales prácticas y creencias. Esto significa presentar un informe sobre ellos que de alguna manera satisfaga los criterios de racionalidad requeridos por la cultura a la cual pertenecen él y sus lectores: una cultura cuya concepción de la racionalidad se halla profundamente afectada por los logros y métodos de las ciencias; una cultura que considera cosas tales como la creencia en la magia o la práctica de consultar oráculos casi como paradigma de lo irracional. Las tensiones inherentes a esta situación llevan muy probablemente al antropólogo a adoptar la siguiente postura: nosotros sabemos 
ras de pensar- se han examinado sin reducirlas a vestigios de formas arcaicas de pensamiento con relación al racionalismo.

La antropología más clásica, en cambio, practicó un reduccionismo racionalista (como forma de incomprensión), identificando como magia, superstición, emotividad o ignorancia prácticas y formas discursivas diferentes a las suyas ${ }^{4}$. El antropólogo era un «reductor de analogías», a las que sacaba de contexto para situarlas en un plano equiparable al del pensamiento racional, pero siempre subalterno. Resultado de ese encuentro, el antropólogo traducía el discurso analógico del pensamiento indígena en discurso racional, un lenguaje común al que reducir los lenguajes de la diversidad humana ${ }^{5}$.

No todas las antropologías se han comportado de la misma manera. Para la antropología biométrica, más interesada en clasificar razas que en comprender universos, o para la antropología orientada a la búsqueda de universales biológicos los intereses van por otro camino. Incluso para una antropología orientada a las bases materiales del comportamiento, interesada en reducir el comportamiento primitivo a costes y beneficios, las analogías poco importan. En este caso, las analogías son poco más que residuos sin interés científico, que no sirven para explicar las bases del comportamiento humano; el materialismo cultural se convierte así en una especie de filosofía de la sospecha, pues indígenas dando cuenta de las razones de la exogamia, reduciendo a costes y beneficios sus movimientos por la selva, o expresando sus hábitos gastronómicos en términos de calorías no han sido precisamente la norma. La realidad está oculta incluso para los nativos. Todo se reduce a coste y beneficio aunque ellos lo ignoren.

«Entonces, ¿por qué mudamos?». La pregunta la dirigía un viejo vaquero pasiego al etnógrafo, viendo que este rechazaba, una tras otra, todas sus explicaciones al no ajustarse a la lógica materialista ${ }^{6}$ ¿ ¿Por qué razón muchos grupos do-

que las creencias zande en la influencia de la brujería, la eficacia de medicinas mágicas, el papel de los oráculos en cuanto que revelan tanto lo que acontece como lo que va a suceder, esas creencias, son erróneas, ilusorias. Los métodos científicos de investigación han mostrado de modo concluyente que no existen relaciones de causa-efecto tales como las supuestas por esas prácticas y creencias. Así pues, todo lo que podemos hacer es mostrar cómo un sistema de creencias erróneas y prácticas ineficaces pueden mantenerse a sí mismo frente a objeciones que a nosotros nos parecen tan obvias», y continúa a pie de página... «En este punto el antropólogo muy probablemente empieza a hablar de la «función social» de la institución en cuestión» (Winch, 1994: 32).

5 «Cuanto mejor sea la traducción...», dice Mary Douglas, «...más perfectamente se habrá impuesto nuestra lógica particular sobre el pensamiento nativo. De forma que la consecuencia de la buena traducción es evitar cualquier tipo de confrontaciones entre sistemas de pensamiento mutuamente ajenos» (1975: 37). Algo que se puede aplicar a toda la antropología reduccionista.

${ }^{6}$ Los pasiegos habitan los montes y los valles en donde nacen los ríos Pas, Miera y Trueba, en la Cordillera Cantábrica. A lo largo del siglo Xx han sido vaqueros, pastoreando con vacas de leche de raza frisona. Todo el territorio está plagado de prados cercados, de propiedad privada, en cada uno de los cuales se ubica una cabaña (prado y cabaña forman una «finca») que permite la residencia conjunta del ganado — en el piso de abajo— y del grupo doméstico — en el piso superior- - . Hasta hace unos años, la mayoría de los grupos domésticos disponían de varias fincas en lugares que no tenían por qué ser contiguos, lo que les obligaba a moverse de un lugar a otro en función de la durabilidad de los pastos en ellas. Este movimiento constante por el territorio era conocido -y lo es aún por los escasos grupos que lo practican-con el nombre de «mudar». 
mésticos pasiegos mudaban — hasta hace poco— sus vacas y trasladaban su residencia incluso entre distancias cortas que podían cubrir fácilmente con un vehículo, un animal de transporte o un paseo? Enfrentado al pensamiento local, ignorando sus explicaciones analógicas (y no analógicas), el reduccionismo productivista pierde la visión del todo en el que está inmerso el movimiento conjunto de ganado y grupo doméstico para indagar hacia adentro, diseccionando con parámetros de rentabilidad cada argumento y atendiendo sólo a explicaciones que se expliciten en esos términos. Pero reducir el pastoreo a cuestión de costes y beneficios no es suficiente para comprender el pastoreo pasiego, pues se trata, como todos, de un pastoreo cultural y, por ello mismo, sagrado ${ }^{7}$.

«Siempre como el caracol, con la casa a cuestas» es una definición (local) analógica para una mentalidad (antropológica) racional. En este ejemplo, se define por relación con el entorno, en donde ha encontrado un elemento que es homólogo: el caracol. El pastoreo es, en este caso, analógico, no racional. Y es también un pastoreo de lógicas alternativas, distintas de las que busca el antropólogo (viviendo con las vacas se está mejor, las vacas estabuladas en el piso inferior dan calor a toda la cabaña, sales de la cama y tienes las vacas debajo), lógicas que apenas pueden resistir una contrastación en términos de costes y beneficios si se arriman al universo de las posibilidades los avances técnicos contemporáneos (mejorar la comodidad en una cabaña en la que centralizar una residencia permanente, acudir a las cabañas en las que se encuentran las vacas en coche como quien va a la fábrica o al trabajo...).

En este sentido, no hay una sola racionalidad, tal y como plantea Peter Winch: hay que dilucidar «el tipo de racionalidad que sirve de contraste» cuando el antropólogo usa términos como «superstición» 0 «irracionalidad», o cualquier otro que signifique modos de hacer y pensar que no se ajusten a los criterios de racionalidad del investigador social ${ }^{8}$.

${ }^{7}$ «El verdadero problema que toda esa razón práctica plantea a la antropología es la existencia de la cultura. Las teorías de la utilidad han mudado a menudo de ropaje, pero siempre interpretan el mismo desenlace: la eliminación de la cultura como objeto distintivo de la disciplina. En la variedad de estas teorías se advierten dos tipos principales, que a lo largo de dos rutas distintas avanzan hacia el mismo fin común. Uno es naturalista o ecológico - por así decirlo, objetivo-, en tanto que el segundo es utilitario en el sentido clásico, o economicista, pues invoca el conocido cálculo sobre medios y fines del sujeto humano racional» (Sahlins 2006: 105).

${ }^{8}$ Jarvie, en su crítica a Winch, consideró que «la posibilidad de constraste y evaluación siempre está presente» en toda sociedad, incluso en aquellas que los antropólogos consideran más aisladas, pues «no existe un "modo de vida" tan aislado y fijo» que no dé opción a la racionalización. Pero además, consideró gradientes en las formas de racionalización, de manera que los criterios de racionalidad azande (sobre los que discute con Winch) parecían «bastante pobres» en comparación con los criterios de racionalidad occidentales, que consideraba «mejores», pues Jarvie criticaba una supuesta concepción de Winch consistente en la incomparabilidad de los criterios de racionalidad entre culturas; crítica que replica éste aclarando que lo que instaba era a preguntarse qué clase de comparación se estaba haciendo y con qué racionalidad se estaban comparando los criterios de racionalidad azande (los argumentos de ambos autores — exposición de Jarvie, comentario de Winch y réplica del primero- se pueden consultar en Jarvie, 1982).

EMPIRIA. Revista de Metodología de Ciencias Sociales. N. . 14, julio-dicembre, 2007, pp. 109-136. ISSN: $1139-5737$ 
El pastoreo del coste y del beneficio es un sistema de encadenamiento de los sucesivos pastos y su aprovechamiento, si bien es sólo una parte y su descripción aislada lo convierte en un listado de técnicas. Comprendiendo el pastoreo como un listado de técnicas (herramientas de trabajo, medios de transporte de la hierba, maquinarias utilizadas, características de los distintos pastos, disposición del pajar y materiales de los que está hecho, etcétera) se pierde la información que une al individuo con el entorno, se vacía a la sociedad de contenido cultural, se ignoran las analogías que asemejan la recogida de la hierba con la reproducción o con la danza o las que unen a otras técnicas de trabajo con el coito... El resultado, en términos analógicos, es un esqueleto y una descripción de los huesos que lo forman, pero que no dicen más que una parte de aquél que lo habitaba.

\section{LA ANALOGÍA SALVAJE Y EL RACIONALISMO PRODUCTIVISTA. ENCUENTROS CONTEMPORÁNEOS}

Los ejemplos más cercanos para ilustrar el pensamiento analógico y el racional representando a las sociedades indígenas y científicas respectivamente se le muestran al antropólogo en su trabajo de campo (pues encuentros a la inversa entre científicos mitopoiéticos y nativos racionales no parecen haber sido comunes en la historia de una disciplina para la cuál la razón es la herramienta indiscutible). En las líneas que siguen, se examinan otros encuentros, esta vez desde la distancia, entre pensamiento analógico y racional, si bien con un tipo de racionalidad distinta de la científica, racionalidad que parece mudable y que, en estos casos, crea argumentos a partir de indicadores de producción y rentabilidad.

La venta y compra de vacas en la Feria de Torrelavega, que se describe brevemente, sólo trata de ejemplificar el encuentro de las dos visiones mencionadas cuando se ponen una frente a otra en un proceso de tira y afloja que, en este caso, se prolonga unas cuantas horas. Es un encuentro más equilibrado que los encuentros que se describen más adelante en los que la visión local tiene pocas posibilidades de triunfar y cuya lectura, en una perspectiva clásica, se orientaría a reconocer el triunfo del productivismo sobre el pensamiento analógico.

Desde su inauguración en 1973 el Ferial de Torrelavega ha sido un espacio propicio para observar dos maneras de actuar que responden a dos formas de entender el mundo ganadero. Una de esas formas la pone en marcha el ganadero, quien trata de vender una vaca analógica; la otra el tratante, que quiere comprar una vaca dialógica? .

Una vaca analógica no es un espectro, es más que una vaca de carne y hueso, más que su producción en leche o en carne. Es una vaca sagrada en el sentido cultural. Una vaca dialógica, en cambio, es una vaca cuyo sentido se argumenta,

${ }^{9}$ Una descripción más exhaustiva de la que se muestra en este trabajo sobre la feria y el complejo analógico en torno a la vaca, se puede consultar en De la Calle, 1999: 379-480.

EMPIRIA. Revista de Metodología de Ciencias Sociales. N. ${ }^{\text {14 }}$, julio-dicembre, 2007, pp. 109-136. ISSN: $1139-5737$ 
como es el caso, hacia su productividad, y en donde cualquiera de sus partes que no sea deudora de su producción no guarda valor alguno. Ambas representan dos concepciones ganaderas diferentes. La primera, una concepción mitopoiética que une a la vaca con su entorno. La segunda, una concepción racional, que une a la vaca consigo misma a partir de un indicador de productividad. La vaca analógica está fuera y dentro de sí; la vaca dialógica sólo lo está dentro. Unas y otras representan dos maneras de pensar, dos discursos diferentes. Lo analógico y lo dialógico son concepciones humanas sobre el entorno, maneras de habitar el mundo que, en este caso, se proyectan sobre las vacas, y reflejan dos universos diferentes.

En el ferial, a lo largo de toda la mañana, los ganaderos hacen todo lo que pueden por vender una vaca que, por ejemplo, es «guapa de la cabeza»o «bonita de la pintura», una vaca que es espabilada, o que tiene buenos andares, buenos cuernos o buenas ubres ${ }^{10}$. Para ello han cuidado su presencia, análogamente a lo que hacen los humanos: la vaca ha sido cepillada, rasurada y peinada, ha tomado vino o café para acudir a la feria alegre y con un aspecto vivo que llame la atención del comprador, y tal vez se la ha dado alguna aspirina para que sus andares se muestren ágiles. También importan la edad y la cantidad de leche, las dos cosas que va a valorar el tratante. Cuanto más joven sea la vaca es mejor, pues su explotación lechera está por venir; los ganaderos tratarán de rejuvenecer a la vaca para llamar la atención del tratante. En cuanto a la producción lechera, el tratante no tendrá una idea aproximada hasta que no se ordeñe, momento en el que también se descubren defectos del ubre. Los tratantes quieren una vaca con argumentos y, para ellos, los argumentos se traducen a litros de leche. En los encuentros entre ganaderos y tratantes, éstos escuchan el discurso mitopoiético del ganadero y «lo ven» en la vaca (a veces no lo descubren dada la perfección de las técnicas analógicas utilizadas: los vendedores tapan las manchas de sarna con betún negro si la vaca es pintanegra, le queman los pelos del ubre para mejorar su aspecto, enrojecen el ubre con colorante para que parezca mejor...) y su primera decisión se puede decir que se hace bajo el influjo del discurso analógico (tanto el que esgrime el ganadero de viva voz como el que se ha encargado de plasmar en la vaca mediante las técnicas descritas y otras). El tratante conoce esas técnicas y siempre está alerta, pide consejo a otros tratantes, a otras personas, escucha todo tipo de informaciones hasta que se formaliza el trato.

La forma más conocida del trato entre el vendedor de analogías y el comprador de litros de leche es el apretón de manos; este gesto no está uniendo dos estilos racionales de pensamiento sino que está tratando de acercar dos estilos diferentes. Conseguir que el trato siga adelante es un éxito: dos universos culturales han llegado a un acuerdo. La feria, y el apretón, se convierten así en un apasionante encuentro de dos maneras de pensar. Hasta el momento, la vaca ha sido

${ }^{10}$ Lo que se narra en estas líneas sobre el comportamiento de compradores y vendedores en la feria se podía constatar en los años centrales de la década de los 90 del siglo XX. No puedo asegurar que estos encuentros se produzcan en la actualidad de la misma forma y en la misma cantidad. La Feria de Torrelavega se ha transformado mucho en los últimos 10 años, hasta el punto de generar dudas sobre su futuro.

EMPIRIA. Revista de Metodología de Ciencias Sociales. N. ${ }^{0}$ 14, julio-dicembre, 2007, pp. 109-136. ISSN: $1139-5737$ 
vendida por técnicas mitopoiéticas; el mercado de Torrelavega no es racional; el animal no se ha vendido al peso con una tasa prefijada; no estamos en una carnicería.

El trato, sin embargo, no ha finalizado. Queda una segunda parte a partir de la cual la venta va a concretarse y definirse (lo que no sucede hasta el momento del pago del precio acordado). La primera parte es lo que se podría llamar la venta mitopoiética de la vaca mientras que la segunda se corresponde con la venta racional: la vaca va a ser ordeñada para escrutar la cantidad de leche y el estado del ubre, y reconsiderar si el precio que se ha acordado minutos antes es o no definitivo. Si la vaca resulta «mala de leche» o con algún defecto en las ubres todo el trato realizado hasta ahora se derrumba; la venta analógica pierde su valor. El precio se reconsidera, bastante por debajo del que se había acordado anteriormente, lo que sitúa al ganadero en una difícil situación pues tras la prueba del ordeño la vaca pierde sus «vistas» y se hace complicado revenderla a otro tratante. Por ello, a menudo el ganadero se ajusta el nuevo precio marcado por el tratante.

No todos los ganaderos caen a la fuerza del discurso productivista. No todos entregan su vaca a cualquier precio tras un ordeño negativo, ni ante el paso del tiempo y la cercanía de la hora de cierre del ferial. No es extraño «volver la vaca» a casa, en cuyo caso ninguno de los dos sistemas de pensamiento ha tenido éxito.

A la vez que suceden estos encuentros en la Feria de Torrelavega, el mundo ganadero cantábrico se está transformando profundamente por la inclusión de España en la UE. La progresiva implantación de políticas europeas en el ámbito estatal va a favorecer la proliferación de encuentros en los que se ven las caras, de un lado, la ideología de las directrices europeas y, de otro, la ideología de las comunidades locales en ámbitos como la pesca, la agricultura y la ganadería.

La entrada de España en la UE y la importación de nuevos cánones productivistas en la construcción de una ganadería de diseño genético es un fenómeno generalizable para toda la Cordillera Cantábrica. La UE impone criterios de racionalidad de tipo productivista (mejorar el rendimiento de las explotaciones), pasando por encima de los criterios y conocimientos locales. Según estos cánones, se potencia la vaca que más kilos de carne «pone» (para las vacas de aptitud cárnica), y la vaca que más litros de leche da (en el caso de las de aptitud lechera): este es, ahora, el único discurso válido, capaz de aplastar la diversidad de las vacas analógicas. Es este el causante de los enfrentamientos entre saberes diferentes que enfrentan a vacas dialógicas y argumentales - animales racionales orientados a la productividad - y a vacas analógicas, criadas culturalmente en los montes de la cordillera por las diferentes sociedades ganaderas. Ámbas concepciones del ganado se encuentran cara a cara y, en los tiempos actuales lo hacen de manera desigual. Corren malos tiempos para lo analógico.

La versión lechera de la vaca productiva que, en los últimos años, ha llenado las medianas y grandes vaquerías cantábricas se define por su rendimiento. En la página web de la Confederacion de Asociaciones de Frisona Española (CONA- 
FE), se pueden consultar las características más sobresalientes en la morfología de la vaca frisona. La descripción de «prototipo racial de la vaca frisona» agrupa diferentes partes del animal en 5 bloques para el caso de las hembras (estructura y capacidad, grupa, miembros y aplomos, carácter lechero y sistema mamario) y 4 para el de los machos (los mismos excepto el sistema mamario). Esos bloques incluyen, a su vez, diferentes partes del animal; así, en estructura y capacidad se incluyen «tórax» y «abdomen» y en carácter lechero, por ejemplo, se incluyen «cuello», «pliegue de la babilla», «muslos», «nalgas», «piel», «cruz» a lo que hay que sumar, en el caso de los machos, los «testículos». Los cinco bloques mencionados se puntúan de acuerdo a un baremo de vaca perfecta. En las hembras el mayor peso lo tiene el «sistema mamario» que puntúa 0,40 puntos sobre 1. En los machos es la «estructura y capacidad», con igual puntuación. En este apartado la descripción del animal (torax, abdomen, cola, cuello, cruz, piel, nalgas, ubre anterior, ubre posterior, venas, textura...) aparece desnuda de cualquier rastro analógico. CONAFE suma, a estas características morfológicas unos «rasgos descriptivos lineales de la raza frisona»:

«De cada animal se evalúan los rasgos descriptivos en base a una escala de medición de cada uno de los rasgos de 1 a 9 . El rango de esta escala de media viene representada por los extremos biológicos del rasgo valorado. De los 21 rasgos descriptivos, 16 (con asterisco) son los que más peso económico aportan en la proyección económica de la explotación ganadera».

Finalmente, un nuevo apartado de su página web informa que «además de la calificación lineal rasgo a rasgo, el calificador evalúa las regiones con las que se obtendrá la calificación final del animal». Las regiones son «sistema mamario», «estructura y capacidad», «patas y pies» y «estructura lechera». De todas ellas la primera tiene un $40 \%$ de peso sobre el total de las regiones de la res.

La descripción de la frisona ya no guarda relación más que con una lógica interna orientada a la producción. Ha perdido toda relación análoga con el entorno y busca dentro de sí una lógica que la sustente. Esa lógica es el peso económico de la vaca medida en su producción lechera. Las partes más significativas de la vaca lo son en cuanto son deudoras de la producción lechera final de la vaca. Pero los cuernos, por ejemplo, ya no cumplen función estética alguna, lo mismo que la cabeza. La «pintura» puede ser bonita pero no vende. Desde el momento en el cualquier elemento significativo de la vaca (la cabeza, el andar, un gesto, o la clase) no guarde relación alguna constable con la producción láctea deja de tener interés. Se puede decir lo mismo de la clase que tenga la vaca o de sus andares. Cualquier descripción de la vaca «hacia afuera de ella» desaparece por su no valor productivo. En las nuevas vacas ya no se ve el peso de las diversas culturas ganaderas. Todas ellas son universales y comparten un lenguaje universal cuyo patrón principal es la producción lechera.

La misma concepción sobre el mundo ganadero (agrícola o pesquero) es aplicable para analizar los efectos culturales de las catástrofes de la modernidad, 
sean ecológicas, alimentarias, sanitarias, etcétera. Releyendo las páginas que escribió García-Allut (2003: 111 y ss.) sobre el impacto emocional del vertido de fuel del buque Prestige en las gentes de la costa gallega de Muxía o Lira no es difícil reflexionar acerca del impacto cultural de una catástrofe de la modernidad. Desde el momento en el que el vertido destroza un paisaje cultural que, por serlo, es racional y más que racional, cualquier búsqueda empírica del impacto debería de comenzar por explorar el efecto que la inundación de fuel crea en los individuos que lo han construido y vivido y que García-Allut concreta con el concepto de «impacto emocional».

Las administraciones, sin embargo, no saben qué hacer con esta modalidad del impacto, pues adopta una postura economicista enfrentando así dos maneras del ver la catástrofe: la que lo reduce a costes y beneficios y la que considera la catástrofe algo cultural cuya cuantificación debería de ir más allá de la mera suma de las horas de trabajo perdidas en la mar.

Estos encuentros posmodernos también encuentran referencias en el mundo ganadero. Con el paso de los años las políticas europeas han intensificado las actuaciones para mejorar la calidad alimentaria de los productos que comemos y la calidad sanitaria de las instalaciones en las que esos productos crecen. Como resultado de la aplicación de estas políticas se ha generado un fenómeno genuinamente contemporáneo: los sacrificios de reses enfermas o de manadas enteras de vacas. El itinerario del proceso es siempre el mismo, y finaliza con la indemnización económica al ganadero (por edad de la res). Acción que no restituye al ganadero al estado previo a las actuaciones, ni siquiera con la compra de un nuevo rebaño, pues el ganadero establece una relación de conocimiento con el ganado que no se obtiene a corto plazo tras reponer la vacada con las indemnizaciones: conoce la procedencia de las vacas, su carácter y comportamiento, sus hábitos, las vacas conocen los terrenos por los que se mueven, los caminos, los establos, y todo como resultado de un proceso dilatado en el tiempo ${ }^{11} \ldots$

El impacto de estas medidas es, ante todo, un impacto cultural, que la administración no puede calibrar, reduciendo las indemnizaciones a euros por kilo de carne o edad de la vaca sacrificada. Vaca llena de símbolos, analogías, recuerdos y significados que no entran en la balanza de la administración y que, por tanto, no son mensurables. La vaca, como el pastoreo, desnuda de sus analogías, se queda en litros de leche, kilos de carne, de la misma manera que el pastoreo quedaba reducido a la cantidad y calidad de los pastos.

Estos escenarios de la modernidad animan a pensar que la generalización y globalización del discurso productivista ha propiciado que lo que hasta hace un siglo era abundante (como los contactos entre indígenas y antropólogos como representantes de dos saberes distintos) sea ahora esporádico; y cierta lógica evo-

${ }^{11}$ En términos analógicos lo expresa un ganadero cabuérnigo diciendo que una manada de vacas nueva es una manada de vacas desconocida: como si uno se mete en la cama con la mujer del vecino, que no sabe por donde va a salir; y no es lo mismo que si uno se mete con su mujer, cuyo comportamiento ya conoce.

EMPIRIA. Revista de Metodología de Ciencias Sociales. ‥ ${ }^{0}$ 14, julio-dicembre, 2007, pp. 109-136. ISSN: $1139-5737$ 
lutiva animaría a pensar que cada vez será más decreciente a causa de la unidimensionalidad del pensamiento rentista y productivista. A su vez, estos encuentros contemporáneos producen la impresión de una relación secuencial que va del primero (pensamiento analógico) al segundo (racionalismo productivista), que se impone y triunfa sobre el pensamiento tradicional. Ilustran bien una visión clásica entre la cultura tradicional que decae y el pensamiento occidental contemporáneo orientado a la producción, que se extiende. Y crean la imagen del fin de la cultura tradicional y la emergencia del pensamiento productivista como discurso unidimensional.

La crisis del trabajo de campo clásico, con largos desplazamientos de espacio y tiempo por parte de los antropólogos, y la proliferación del antropólogo urbano estarían dando cuenta, como indicadores en sí mismos, de la desestructuración de las comunidades indígenas y tradicionales por el triunfo del productivismo sobre la variedad cultural.

\section{LO SALVAJE DE LA ANALOGÍA (I). LA ANALOGÍA SALVAJE Y EL ORIGEN DE LA CULTURA PASIEGA}

En este apartado trataré de argumentar que el pensamiento salvaje está en la historia, como lo están otros tipos de pensamiento. Esto me llevará a considerar su naturaleza en relación a otras formas de pensar, especialmente el racionalismo y, más en concreto, el racionalismo productivista. El objetivo es reinsertar la analogía salvaje no en las sociedades en sí (pues todas las sociedades muestran formas de pensamiento analógicas), sino en la historia de esas sociedades, explorando sus apariciones y desapariciones en relación a otras formas de pensar.

Esto permitirá revisar lo examinado hasta ahora en los apartados anteriores: la existencia de dos universos culturales en torno a las vacas, y la idea de que una concepción analógica del ganado está siendo sustituida por una concepción productivista. Esta doble revisión trata, por un lado, de suavizar la idea de que unas sociedades son sólo analógicas (como las primitivas y tradicionales) y otras sólo racionales (como las científicas) o productivistas (como la sociedad contemporánea), pues se verá que ambos tipos de pensamiento emergen o se hacen más visibles en ciertos momentos históricos en las mismas sociedades. Por otro lado, me permitirá criticar la idea de una relación secuencial que va del pensamiento analógico al pensamiento racional y productivista, pues espero mostrar que ambos se ocultan y emergen sin esa lógica evolutiva.

La visión dualista tan drástica entre pensamiento indígena y pensamiento científico, ha recibido crítica por su representación excluyente de la distribución del pensamiento humano ${ }^{12}$. La crítica viene a resaltar que sociedades primitivas

${ }^{12}$ Como es el caso de Jack Goody, crítico con esta visión dualista tan radical de las sociedades como criterio clasificatorio y teórico pertinente (1985: 11-28). Concretamente con las nociones que hacen referencia al pensamiento indígena. La consideración de las sociedades primitivas como mi-

EMPIRIA. Revista de Metodología de Ciencias Sociales. N. ${ }^{\circ}$ 14, julio-dicembre, 2007, pp. 109-136. ISSN: 1139-5737 
y modernas lo fueron mientras los antropólogos representaron a «ellos» (y, por extensión, a «nosotros») como dos maneras de pensar perfectamente delimitadas (y alejadas una de otra), de manera que daba la sensación de que «ellos» sólo eran mitopoiéticos y «nosotros» sólo racionales ${ }^{13}$. Lévi-Strauss identificó el discurso mitopoiético como un discurso distinto del científico, con el que no se podía situar en ámbito comparativo. Espero no interpretar mal al autor francés cuando digo que participó de la idea de la existencia de dos universos excluyentes, el de los indígenas con su pensamiento salvaje y el de los científicos con su pensamiento domesticado, exclusivamente, por mucho que en un estado primigenio ambos formaran una unidad ${ }^{14}$. Tal vez por ello, en «El Pensamiento Sal-

tológicas en una parte de la tradición antropológica como la que representa Lévi-Strauss incluye un tratamiento simbólico más que cognoscitivo (35), de manera que en ellas no hay lugar para un proceso creativo intelectual. Y es precisamente por esto por lo que interroga las teorías de Durkheim o Lévi-Strauss, puesto que la actividad creadora y artística de ciertos individuos también se constata en las sociedades primitivas, si bien queda integrada dentro de la «sociedad» o la «cultura» y no tanto dentro de un bagaje personal: «Aún en las sociedades ágrafas no hay evidencia de que los individuos estuviesen prisioneros de esquemas preordenados, de clasificaciones primitivas, de las estructuras del mito. Limitados, sí; aprisionados, no. Al menos algunos de entre ellos pudieron, y así lo hicieron, usar el lenguaje de una manera creadora, elaborando metáforas, inventando canciones $\mathrm{y}$ «mitos», creando dioses, buscando nuevas soluciones para abordar rompecabezas y problemas, cambiando el universo conceptual» (43). Para Goody, «las sociedades tradicionales no están marcadas tanto por la ausencia de pensamiento reflexivo como por la ausencia de las herramientas propias de la meditación constructiva» (56) como es el caso de la escritura, que permite examinar un discurso, criticarlo y dar paso a la lógica y la racionalidad con las que caracterizamos a las sociedades contemporáneas.

13 Además de usar mitopoiesis y racionalismo en diferentes momentos o ámbitos de la cotidianeidad, las posibilidades del pensamiento y la práctica parecen ir más allá de la simple dualidad de esta visión clásica, como se muestra en el trabajo de Detienne y Vernant (1988).

${ }^{14}$ Según Lévi-Strauss, «el corte, la separación real entre la ciencia y aquello que podríamos denominar pensamiento mitológico - para llamarlo de alguna manera, aunque no sea ése el nombre exacto- tiene lugar durante los siglos XVII y XVIII. (...) Es probable que este movimiento haya sido necesario pues la experiencia nos demuestra que gracias a esta separación —este cisma, si se quiere- el pensamiento científico halló las condiciones para autoconstituirse» (1990: 24). Sin embargo, este cisma del que habla el antropólogo francés parece no haberse concretado nunca. Sabemos que el pensamiento analógico forma y ha formado parte de la evolución de la ciencia, de manera que donde no ha llegado el pensamiento racional ha llegado el analógico. La ciencia ha perseguido siempre un mito, dice Lizcano (2006), consistente en la posibilidad de un «conocimiento puramente racional», «conocimiento puro, sin mezcla de residuos míticos ni de creencias espurias» (p. 241); la purificación de su trabajo ha exigido al científico la eliminación de lo residual mediante sus propios ritos de purificación como la abstracción y el análisis; lo residual estaría formado por todas aquellas actividades intelectuales no estrictamente racionales entre las que se encuentran las metáforas y también las analogías: «la analogía entremezcla, difumina, ensucia los límites que los procesos abstractivos y analíticos tanto se esfuerzan en distinguir. (Sin embargo, como sin analogía es imposible el pensamiento, siempre quedará ese residuo analógico que es el signo igual de las ecuaciones, por el que todo buen científico sabe que no debe interrogarse si no quiere enfangar el limpio fluir de una secuencia demostrativa)» (p. 244). Más relacionado con la moda y el rédito personal -que con un uso no consciente de estos recursos intelectuales- es el abuso posmoderno de la analogía en algunos filósofos sociales franceses que critica Bouveresse (siguiendo la estela del affaire Sokal y el trabajo posterior de este y Bricmont que criticaba los procedimientos literarios absurdos, sin base científica y sin fundamento alguno de un cierto número de filósofos franceses con-

EMPIRIA. Revista de Metodología de Ciencias Sociales. N. ${ }^{0}$ 14, julio-dicembre, 2007, pp. 109-136. ISSN: $1139-5737$ 
vaje» no ahondó en la relación secuencial entre racionalismo y mitopoiesis en una sociedad dada, ni su convivencia, ni la posibilidad de que las sociedades indígenas mostraran discursos racionales, ni de los tipos de racionalidad que mostraban, ni del contexto histórico en los que uno u otro se muestran más visibles o, por el contrario, se recogen.

Este tipo de trabajos no ha recibido una atención importante en el ámbito de las que fueron llamadas «sociedades primitivas», a las que conocemos más por sus actividades y maneras de pensar consideradas no racionales. La literatura antropológica ha sido mayoritariamente buscadora de mitos, analogías, metáforas y recursos intelectuales de estructura no argumental, y ha dejado de lado formas de pensar y actuar que le resultaban más lógicas, o que mostraban una lógica familiar ${ }^{15}$. En cuanto a las «sociedades tradicionales», en cambio, hay una larga tradición de estudios orientada a examinar los comportamientos racionales de los agricultores, ganaderos o pescadores, a los que han identificado como tomadores de decisiones, como individuos calculadores con estrategias adaptativas, etcétera.

También los pasiegos se muestran racionales a la vez que analógicos. No hay información suficiente para cotejar si los pasiegos son más o menos analógicos que pueblos vecinos como los purriegos, sobanos, campurrianos, lebaniegos..., aunque la cuestión tiene atractivo antropológico. El imaginario colectivo regional tiene a los pasiegos por gentes extrañas, no sólo racialmente, - como si de un grupo social extraño a un supuesto tronco común racial del resto de habitantes de la región mayor- sino también en su comportamiento. Los estereotipos, negativos las más de las veces, colocan a los pasiegos en universos extraños. Raros, introvertidos, recelosos... Uno de los estereotipos más recurrentes sobre

temporáneos) y que se concreta a partir de dos principios: «(1) Poner sistemáticamente en relieve las semejanzas más superficiales, presentando esto como un descubrimiento revolucionario» y (2) «ignorar también de manera sistemática las diferencias profundas, presentándolas como detalles desdeñables que no pueden interesar más que a los espíritus puntillosos, mezquinos y pusilánimes» (2001: 38). El abuso filosófico de la analogía es, para Bouveresse, un vicio posmoderno que se escapa al control científico precisamente en una disciplina difícil de controlar, que defiende el «libre vuelo del pensamiento»: «no disponemos todavía, no ya de una verdadera teoría de la analogía (lo que quizás es mucho pedir), sino ni siquiera de una concepción aproximativa de lo que podría constituir un uso filosófico regulado y relativamente disciplinado de ésta, susceptible de conducir a resultados a la vez aceptables e interesantes. Y los filósofos prefieren evidentemente conservar el derecho de utilizar como mejor les parezca todas las analogías que pueden presentarse en cualquier momento, desde las más reales e importantes hasta las más superficiales y tramposas (que no son por lo general las menos excitantes), en lugar de interesarse seriamente en estas cuestiones» (ibidem, p. 50). En el trabajo de Bouveresse no se habla de crisis del pensamiento racional en Filosofía, ni de fases o secuencias del pensamiento, ni se da importancia histórica a este movimiento - desordenado- de la analogía. Son los efectos estéticos que se consiguen con su uso y los beneficios particulares adjuntos las razones de la invasión posmoderna de la analogía libre y desbocada.

${ }^{15}$ La mentalidad indígena mitopoiética sigue siendo una constante en la búsqueda antropológica. Aún en la actualidad, buscar por la selva del Amazonas grupos indígenas que aún no hayan entrado en contacto con nuestra sociedad para toparse con discursos racionales sería algo sorprendente para la imaginación antropológica. Y, por supuesto, tribus que expliciten sus actos en términos que llamamos racionales perderían todo su salvaje glamour (también lo perdería el antropólogo), componente oculto en la búsqueda antropológica pasada y presente.

EMPIRIA. Revista de Metodología de Ciencias Sociales. N. ${ }^{0}$ 14, julio-dicembre, 2007, pp. 109-136. ISSN: $1139-5737$ 
los pasiegos los tilda de «peseteros», como algo especialmente significativo con relación a otros grupos de población. En un plano más académico se les ha considerado, en cambio, artífices de un cambio casi revolucionario, al introducir la apropiación privada de la tierra en un espacio, como el montañés, mayoritariamente comunitario. Y también se les ha considerado los introductores de la vaca frisona en la región y se les ha tenido por comerciantes a unos niveles superiores al resto de los habitantes de los valles cantábricos. La austeridad de su modo de vida, en perspectiva comparada, su interés en el comercio, la individualidad como característica frente al colectivismo montañés, animan a pensar en una sociedad racional, menos dada que otras de su entorno a construcciones intelectuales no estrictamente racionales. Y, aunque la imagen dada en estas páginas muestra a sus vacas como construcciones analógicas, los pasiegos también sostienen argumentaciones productivistas de las vacas (interés por el número de litros de leche) y elaboran representaciones de las vacas en clave de producción, como cuando se dice de una vaca que «no hace más que comer y hacer abono», reduciendo al animal a una máquina de ingerir y expulsar entre medias de cuyos procesos no genera beneficio alguno (no produce leche). El pensamiento racional productivo también forma parte del pensamiento cultural, y en este caso de la concepción del ganado vacuno, pero de él es sólo una parte.

La suposición de dos modos de pensamiento excluyentes, ha podido generar el supuesto implícito en el pensamiento antropológico clásico de una lógica evolutiva que lleva desde el pensamiento analógico al racional, de manera que los indígenas parecen ser con el paso del tiempo menos mitopoiéticos como resultado del contacto prolongado con una sociedad global que, teóricamente, impone formas de entender el universo en términos de rendimientos y productividades ${ }^{16}$.

En el ejemplo de estas páginas lo salvaje está representado por la analogía en torno a las vacas y lo domesticado por un pensamiento de tipo dialógico orientado a un rendimiento. Y aunque la impresión de los encuentros entre ambos saberes sugiere una sustitución de uno por otro, el racionalismo productivista (en los ejemplos que estamos analizando) no es una fase posterior al pensamiento analógico. En el ejemplo utilizado en el apartado anterior para exponer el aspecto racional, limpio de analogías, de la morfología de la vaca frisona según consta en la página web de la CONAFE, se han colado dos comentarios analógicos. Cuando se describe la «estructura y capacidad» de las hembras, dice: «individualidad que denote vitalidad, feminidad, estilo...» (en la descripción de los machos sus-

16 Aunque, a la vez, también tenemos la sensación que los antropólogos son menos racionalistas como resultado de la crítica antropológica hacia la metodología objetivista, racionalista y distante levantada desde los cimientos malinowskianos. Crítica que coincide con la inclusión del cuerpo en la teoría social y el reconocimiento del individuo (y del antropólogo) como un «sujeto-cuerpo», tal y como se mostraba Malinowski, según James Clifford, en sus diarios de campo en Melanesia (Clifford, 1999: 92). Coincidiendo con la inclusión del cuerpo y la crítica al objetivismo, la emergente Antropología de la Sexualidad también ha llamado la atención sobre la dificultad de mantener la postura distante y objetiva del antropólogo durante el trabajo de campo (Nieto 1989: 19 y ss.; Nieto 2003: 39-48;).

EMPIRIA. Revista de Metodología de Ciencias Sociales. N. ${ }^{\circ}$ 14, julio-dicembre, 2007, pp. 109-136. ISSN: $1139-5737$ 
tituye feminidad por masculinidad), lo que indica que a un proceso de destrucción de las vacas culturales por vacas productivas le sigue un proceso de reconstrucción de una realidad que, en un principio, se mostraba como puramente racional. Lo mismo sugieren algunos de los comentarios que hizo el juez catalán que puntuó el VIII Concurso Nacional de Ganado Frisón (de primavera) que se celebró en el ferial de Torrelavega en marzo de 2005; según recogió la prensa local, en su opinión la vaca ganadora era «una vaca atractiva, femenina, estilosa, fuerte, buena costilla y gran sistema mamario» ${ }^{17}$.

La vaca había sido desprovista en un primer momento de sus analogías para, mediante una práctica argumentada (mayor productividad), proceder a la introducción de las nuevas vacas de diseño. Este proceso ha debido de ser más extremo en los primeros momentos de choque entre dos visiones ganaderas que ahora, pues el objetivo de animar a los ganaderos a cambiar sus ganados analógicos por los nuevos sólo se podía hacer mediante argumentos racionales que desmontaran cualquier rastro cultural. Sin embargo, conseguido ya el cambio, el mismo discurso racional apenas puede evitar construir cultura y dejar escapar sus analogías para, en definitiva, rellenar de cultura una vaca puramente racionalizada. Desculturización de la vaca, racionalización y enculturación, las tres fases del proceso de cambio de un ganado por otro. El racionalismo parece mostrarse, en nuestros ejemplos, como una forma discursiva que se pone en guardia en períodos de cambio mientras que el pensamiento analógico parece que se desarrolla en momentos de estabilidad social.

El proceso que alimenta la impresión de una evolución hacia el pensamiento productivista es, pues, un momento histórico, tras el cual resurge en un nuevo ambiente la analogía. Si retrocedemos 100 años en la historia de los pasiegos, encontramos un proceso similar. Corren los años en donde se origina la sociedad pasiega contemporánea, el momento histórico en el que se produce un cambio brusco en el universo cultural de los pasiegos, cuando una época en la que domina la razón productivista aparta de las prioridades culturales a la analogía. Momento a partir del cual reflexionar de nuevo sobre el racionalismo y la analogía, tanto juntos como secuenciales.

Los pasiegos han llevado - en términos generales - una vida nómada durante prácticamente todo el siglo Xx. Uno de los últimos cambios bruscos que transformó su sociedad se produjo en el último cuarto del siglo XIX, cuando introdujeron la vaca holstein de raza frisona sustituyendo con ella a una vaca autóctona que los estudiosos han dado en llamar «pasiega». El cambio al pastoreo del frisón produjo cambios sociales y culturales de grandes dimensiones. La sociedad pasiega que conocemos y conocimos en las últimas décadas del siglo XX era la consecuencia de aquellos cambios de finales del siglo XIX. Los cambios fueron tan bruscos como para hablar de una nueva forma de ser pasiego; nueva identidad pasiega y nuevo complejo cultural en torno al cultivo del ganado frisón, nuevas analogías y nuevas maneras de unir la vida con el entorno. Los au-

${ }^{17}$ Diario Montañés, 24 de marzo de 2005, p. 20. 
tores que han mencionado este momento histórico siempre han prestado más atención a las características productivas de la nueva vaca que a otro tipo de cuestiones: la vaca frisona daba más leche que su antecesora aunque con menos porcentaje de grasa. Los pasiegos comenzaban así una especialización en la recría de vacas y en la producción de leche en grandes cantidades destinada, en un principio, a las vaquerías de grandes ciudades. Su actividad ganadera se intensificó y otras actividades económicas empezaron a perder peso.

«La extraordinaria demanda que de leche había en las ciudades donde los pasiegos habían establecido vaquerías, les llevó a buscar un tipo de vaca de mayor producción láctea, para lo cual, y entre el 1865 y 1870, iniciaron el cruce de la pasiega con la suiza, obteniendo buenos resultados; pero a pesar de ello, no quedaron satisfechos, empezando los vaqueros (pasiegos) de Madrid la importación del ganado holandés, que por algunos ejemplares llegados a esta provincia habían podido ver sus magníficos resultados» (Arche, 1945: 61).

«Su producción de leche era pequeña (la de la vaca indígena), pues no llegaba a los seis litros diarios, pero esta cantidad quedaba compensada por la riqueza en principios grasos, que llegaba hasta un 7\%, lo que justifica su fama y el precio que alcanzaba en los mercados. Esta riqueza constituía la base de la elaboración del queso y mantequilla, principal industria de las villas pasiegas (hasta el cambio de vaca). (...) Al mediar el siglo, el pasiego inicia ya el desplazamiento hacia las capitales, Santander, Bilbao, Zaragoza y Madrid, en donde las mejores y más acreditadas vaquerías para la venta de leche fresca fueron pasiegas. (...) El consumo creciente de leche en las grandes capitales y el establecimiento en la provincia de fábricas de queso y mantequilla, determinaron un aumento en la demanda del producto en el mercado y fue necesario forzar la producción. Primero se ensayó el cruce con la vaca suiza, hacia 1870, y después se recurrió a la holandesa, que llegó a imponerse en la comarca rápidamente, con desaparición de la variedad indígena» (De Terán, 1947: 521-522).

Como la demanda era mayor que sus posibilidades, comenzaron a realizar cruzamientos de la raza Pasiega con la Suiza con lo cual lograron una heterosis (sic), mayor producción y un porcentaje elevado de grasa. Pero ellos lo que deseaban era un tipo de vaca adaptada a la producción láctea que diera un máximo de producción, aunque la leche fuera menos grasa. Su experiencia con las razas extranjeras les condujeron a elegir como la más adecuada para su industria la raza Frisona (Madariaga, 1970: 188).

Hay poco más que este tipo de información para argumentar sobre ello, pero se infiere que el discurso racional se antepuso a cualquier otro en torno a la conveniencia de adoptar la vaca frisona como nueva vaca para los montes pa$\operatorname{siegos}^{18}$. Estos textos indican que el pensamiento racional en torno a la elección

${ }^{18}$ Han argumentado de la misma forma Ortega, que habla de «giro productivo» de los pasiegos desde la producción de mantequilla a la producción de vacas lecheras, giro con el que los pasiegos muestran «su ágil percepción de las condiciones del mercado de que depende» (1975: 893); y Tax Freeman, para la que los pasiegos «aprovecharon la oportunidad de aumentar la producción lechera» con la introducción de la vaca frisona, y habla del «deseo general de aumentar el censo vacuno para una mayor producción mercantil» (1986: 33). 
de la vaca, basado en ese tipo de indicadores (cantidad de leche y una demanda creciente) resultó crucial para poner en marcha un cambio muy fuerte; cambio que trajo consigo una reordenación del universo pasiego, cuya característica más significativa fue la creciente estabilización del sistema de vida pasiego en su hábitat, a diferencia del período anterior en el que las necesidades económicas no cubiertas en el propio territorio obligaban a los grupos domésticos (y tanto a hombres como a mujeres) a salir a comerciar fuera de los montes pasiegos.

Sin embargo, cien años después de la introducción de la raza frisona, a comienzos de la década de los 90 del siglo Xx, los pasiegos «habían construido una vaca» en la que lo racional era sólo una parte.

Envuelta en analogías, la vaca era entendida como una mujer durante el parto o el posparto, o como una persona cuando estaba enferma; cuando acudía a una feria era entendida como una mujer el día de su boda. Los pasiegos se movían de lo conocido (humano) a lo desconocido (animal) por vía analógica ${ }^{19}$. Las vacas también hablaban del vaquero que proyectaba en ellas entusiasmo, esfuerzo, cariño, tesón (mira a la vaca y estarás mirando al vaquero); tenían presencia, clase, estilo, estética, tenían un gesto, una forma de andar, un cuerpo, una cabeza, una «pintura» y se las describía con multitud de conceptos que permitían seguir conociendo a las vacas por analogía: el ubre «hace cueva»..., la cabeza tiene «una estrella»..., descripciones que unen el cuerpo de la vaca con todo.

La vaca pasiega estaba unida con todo, era una vaca mitopoiética por muy racional que se nos presentara el proceso de su adopción y la sustitución de su antecesora. Incluso la parte más productiva del animal era sometida al criterio de la cultura: cuando la vaca enubraba bien tras el parto decían que la vaca «enubra de $\operatorname{arte} »^{20}$.

Si admitimos que el cambio que se produce a finales del siglo XIX está basado en cálculos, observaciones y argumentaciones de tipo racional sobre nuevas razas vacunas, no es difícil imaginar que la racionalización en ese período de cambio en el universo pasiego apartara u ocultara anteriores analogías entre las

${ }^{19}$ Creo que las palabras de Lévi-Strauss orientadas a dar cuenta de mitos y ritos en las sociedades indígenas se pueden aplicar aquí para dar cuenta de las prácticas analógicas de los pasiegos sobre las vacas frisonas: «métodos de esta índole podían conducir a determinados resultados que eran indispensables para que el hombre pudiese atacar a la naturaleza desde otro flanco. Lejos de ser, como ha menudo se ha pretendido, la obra de una «función fabuladora» que le vuelve la espalda a la realidad, los mitos y los ritos ofrecen como su valor principal el preservar hasta nuestra época, en forma residual, modos de observación y de reflexión que estuvieron (y siguen estándolo sin duda) exactamente adaptados a descubrimientos de un cierto tipo: los que autorizaba la naturaleza, a partir de la organización y de la explotación reflexiva del mundo sensible en cuanto sensible. Esta ciencia de lo concreto tenía que estar, por esencia, limitada a otros resultados que los prometidos a las ciencias exactas naturales, pero no fue menos científica, y sus resultados no fueron menos reales (2005: 34-35).

${ }^{20}$ Tras el parto las vacas tienen un «golpe de leche» que rellena sus ubres y que, estéticamente, resulta llamativo. Los pasiegos venden sus vacas a los pocos días de parir de manera que acuden a la feria con el ubre repleto (que los ganaderos facilitan cerrando los orificios de las tetas con pegamentos o pinzas para evitar que pierda la leche y pierda «vistas»).

EMPIRIA. Revista de Metodología de Ciencias Sociales. N. ${ }^{\circ}$ 14, julio-dicembre, 2007, pp. 109-136. ISSN: 1139-5737 
cuales habría que considerar a las que afectaban a las vacas indígenas que, desde estas fechas, comienzan a desaparecer de los montes pasiegos hasta su extinción. También es probable que algunas analogías simplemente mudaran de vaca como por ejemplo aquellas en las que vaca y mujer son tratadas de la misma forma tras el parto, aplicables en el caso de la vaca indígena como en el caso de la frisona ${ }^{21}$.

Finalmente, otras analogías se crearon ex-novo. No sólo las que se derivan de la adquisición en el universo local de una vaca morfológicamente distinta como la frisona sino, también, de los nuevos usos a los que se va a someter a la nueva vaca, como su venta pública, práctica que se convertirá en masiva con el devenir de los años, e inusual hasta entonces. Con relación a lo primero, la frisona se envuelve con analogías que sólo las soporta una vaca pintanegra o pintarroja como las frisonas, como cuando se dice que la vaca tiene una estrella en la frente, analogía sin sentido en la vaca pasiega ya extinta de «poca alzada, cuernos finos y cortos, capa colorada y clara, cabeza pequeña y graciosa, extremidades proporcionadas y finas» (López, 1888: 146). Con relación a lo segundo, aparece un sistema analógico más complejo que se puede traducir como sigue: «una vaca cuando se va a vender es como una mujer el día de su boda», y que engloba un conjunto de prácticas sobre la vaca cuyo objetivo es presentarla en un espacio público, permítaseme la analogía, el día más importante de su vida. Prácticas desconocidas para los pasiegos hasta la inclusión de las vacas holandesas pues la indígena permanecía recluida en los montes para explotación del grupo doméstico mientras que la recría y venta de vacas para su explotación lechera por otros será una característica importante de la pasieguería desde los primeros momentos de adquisición del ganado holandés.

El proceso de cambio de la sociedad pasiega de la última parte del siglo XIX demuestra que dado que buena parte del complejo analógico en torno a la vaca holandesa es novedoso (aunque se establezca siempre entre las mismas partes, hombre/animal) en este sentido la analogía surge después de un proceso de racionalización de la producción. Tras un período de cambio dominado por el pensamiento racional -en el que se importa una vaca que impone nuevas exigencias al pastoreo-, la sociedad pasiega construye una cultura nueva, de la que se ha examinado en las líneas previas el complejo analógico en torno a la nueva vaca frisona. Podemos inferir que, una vez hecho el cambio - cuando la vaca frisona es mayoritaria en los prados pasiegos-, la cultura se explaya y conquista el entorno mediante la impronta que dejan tanto hombres como mujeres. El ejercicio racional de finales del XIX se suaviza y adopta una posición más atem-

\footnotetext{
${ }^{21}$ Prácticas posparto análogas entre mujeres y vacas de razas no frisonas han sido documentadas por María Cátedra entre los vaqueiros de alzada (1979, especialmente p. 57 y ss.). Por su producción se trataba de una vaca más parecida a la vaca indígena pasiega que a la frisona, una vaca «poco lechera comparada con otras, que precisan permanecer estabuladas, pero su leche es muy rica en grasa y resulta idónea para alimentar terneros; por ello la producción de carne ha constituido la principal función del ganado en la braña» (Cátedra, 1989: 129-130).
} 
perada en el universo cultural local, como lo muestra el hecho de que cien años después encontremos a los pasiegos defendiendo un discurso analógico en las ferias de vacas allí donde sus antecesores habían adoptado un discurso racional para incorporar a sus cuadras a ese mismo animal.

El desarrollo histórico de este proceso cuestiona una concepción clásica de la antropología acerca de la relación secuencial entre analogía y racionalismo, entre pensamiento mitopoiético y pensamiento racional. La concepción clásica en antropología de que el pensamiento mitopoiético era «pre-lógico» sugería la idea de una evolución del pensamiento hacia la racionalidad como forma superior del intelecto. Analogía y racionalidad no son, como se ve, evolutivas. No se trata de una secuencia histórica de manera que la humanidad completa se encamine hacia formas de pensar racionales por superación de otras formas de construir universos de sentido. En el caso examinado, la analogía, por decirlo así, crece y se expande desde un estado de racionalidad. En la historia de las sociedades hay secuencias temporales analógicas y otras racionales, pero no son evolutivas de manera que el pensamiento analógico fuera primitivo o arcaico y el pensamiento racional moderno o progresista y mantuviera con aquel una relación secuencial de manera que viniera a sustituirle progresivamente dada una supuesta mayor adecuación a la realidad (Lévi-Strauss, op. cit., p. 43). Todo el trabajo de Lévi-Strauss en «El pensamiento salvaje» está orientado a mostrar su peculiaridad y su complejidad, de manera que no se puede colocar en una línea evolutiva cuyo eslabón superior estaría representado por el pensamiento científico.

Pero el proceso de cambio de la sociedad pasiega a finales del XIX también cuestiona la concepción de las sociedades indígenas y tradicionales como «sólo» mitopoiéticas. Las relaciones entre analogía y racionalización que se han examinado en el caso del cambio cultural pasiego de finales del XIX no resultan aclaratorias para establecer el carácter salvaje del pensamiento analógico, entendiendo por carácter salvaje una condición originaria e inmutable del intelecto humano, no sometida al vaivén de los momentos históricos o de las situaciones y acontecimientos que exigen otras maneras de pensar. Pensamiento analógico y racionalismo no son pensamientos excluyentes, ni la secuencia temporal que generaliza en la actualidad un pensamiento racional de tipo productivo anima a pensar en una crisis definitiva del pensamiento analógico; e, incluso, la analogía puede aparecer tras un proceso de racionalización de este tipo. En ciertos momentos históricos un tipo de pensamiento puede ser más visible que el otro, puede haber fases en los que a nivel cultural se constate el uso de un pensamiento racional y fases en las que emerja el pensamiento mitopoiético, pero el carácter salvaje no parece que esté exento de un contexto histórico que, digámoslo así, lo facilita.

Lo salvaje del pensamiento salvaje, de la analogía o de la metáfora salvaje, parece estar, entonces, relacionado con momentos históricos en donde uno u otro se hacen más visibles o centrales. Lo que de salvaje tiene el pensamiento salvaje parece, pues, guardar relación con los procesos por los que transitan las diferentes sociedades en donde se declinan hacia una u otra de estas formas discur- 
sivas. Pero ambos lenguajes, siguiendo a Morin, «no forman sino uno en nuestro lenguaje ordinario ${ }^{22}$. La actual crisis del sistema analógico de pensamiento no es definitiva. Sí lo es, posiblemente, el tipo de analogías que va entrando en desuso, pero no la analogía en tanto cultura. Analogía y racionalización no son evolutivos de manera que el segundo sustituya definitivamente al primero. La analogía como expresión cultural sólo se repliega ${ }^{23}$.

22 «Las antiguas analogías mitológicas han muerto en nuestras creencias contemporáneas, pero siguen vivas en nuestras afectividades, nuestros estados del alma y nuestra poesía. Nuestro lenguaje está colmado de transportes analógicos de un dominio a otro, que se han vuelto casi invisibles (la salida del sol, las raíces del mal, la explosión de un amor). La expresión de persona a persona se hace por proyección de sí a otro, identificación de otro consigo, en una vivencia analógica en la que el otro, ego alter, se convierte en alter ego. El conocimiento científico mismo, que en su fase simplificadora creyó expulsar la analogía, la utiliza sin saberlo (la selección natural, las leyes de la naturaleza). Como hemos indicamos más arriba, la racionalidad practica la analogía, aun cuando la somete a exámenes y verificaciones. La analogía emprende el vuelo más libre en el pensamiento poético y el pensamiento mitológico... (...) Una de las riquezas del lenguaje ordinario es que combina uno y otro lenguaje, y traduce de este modo la complejidad afectivo-racional de lo humano. Cuando pretende ser sobre todo racional, el discurso se desarrolla bajo un fuerte control empírico y lógico, tiende a reducir sus elementos analógicos a comparaciones, sus elementos simbólicos a signos o convenciones. Cuando pretende ser poético, el discurso se deja llevar por la música de las palabras, las asonancias, las imágenes (pero de ningún modo excluye el control) (Morin: 2004: 110-112).

${ }^{23}$ Sahlins, defendiendo la impronta cultural del comportamiento humano frente a las teorías utilitaristas de la determinación económica y la lógica práctica, considera que la distinción entre nuestras sociedades y las primitivas no está en una diferente forma de ver el mundo, como si nosotros hubiéramos despojado toda simbólica de una vida en la que «la economía parece dominante» y los primitivos vivieran inmersos en ella, en un mundo en donde todo está «bañado en una luz celestial» (op. cit., p. 209). Estas observaciones, en cambio, remiten a diferentes «ámbitos dominantes de la producción simbólica». Lo que nosotros identificamos como utilitarismo o ámbito económico, - como opuesto al simbólico de los primitivos-, es símbolo también, con la diferencia de que en nuestras sociedades «el simbolismo económico es estructuralmente determinante». Digamos que la diferencia entre la sociedad occidental (que Sahlins identifica también como sociedad «burguesa») y la primitiva está en la naturaleza de la simbolización: «... la peculiaridad de la cultura occidental consiste en la institucionalización del proceso (simbólico) en la producción de bienes y bajo la forma de ella, en comparación con un mundo primitivo donde el lugar de la diferenciación simbólica sigue siendo el de las relaciones sociales, principalmente las relaciones de parentesco, y las otras esferas de la actividad son ordenadas por las distinciones operativas de parentesco. La cuestión no tiene que ver tanto con el dominio funcional como con lo estructural, y con diferentes estructuras de integración simbólica. Y a este diferencia general de esquema corresponden diferencias en el empeño simbólico, es decir entre un código abierto, en expansión, que responde, mediante una transformación continua, a los hechos que el mismo ha desencadenado, y un código aparentemente estático, que no parece entender de hechos sino de sus propias concepciones. (...) Ambos órdenes institucionales elevan ciertas relaciones institucionales a una posición de dominio, como lugar desde el cual es aplicada la retícula simbólica, y el código es objetivado. En la sociedad burguesa, la producción material es el lugar dominante de la producción simbólica; en la sociedad primitiva, ese lugar es el conjunto de las relaciones sociales (parentesco)». El carácter simbólico del proceso económico pasa inadvertido para sus usuarios pues para ellos «la diferenciación del valor simbólico es mistificada como la apropiación del valor de cambio». En la sociedad occidental, pues, «la lógica de la producción es una lógica diferencial de los significados culturales» (ibid., pp. 209-211). La tesis de Sahlins, sin embargo, no aporta mucho a la hora de examinar las relaciones entre ambos tipos de pensamiento. Que en ambas sociedades (la occidental y la primitiva) el simbolismo sea determinante y que la diferencia entre ambas sea una cuestión de la naturaleza del simbolismo lo que hace

EMPIRIA. Revista de Metodología de Ciencias Sociales. N. . 14, julio-dicembre, 2007, pp. 109-136. ISSN: 1139-5737 


\section{LO SALVAJE DE LA ANALOGÍA (II). LA BASE SOCIAL DE LA ANALOGÍA SALVAJE}

El cuerpo de la vaca es una imago mundi (Lévi-Strauss, 2005, op. cit., p. 93); en él aparecen representados muchos elementos de la naturaleza. Sin embargo, una parte de la teoría social posterior a Lévi-Strauss, con el que se muestra crítica, nos ha enseñado que estos universales no se pueden separar de las condiciones sociales de producción. La teoría social contemporánea ha exigido con el paso de los años que interroguemos a los nativos y nos interroguemos a nosotros mismos acerca de esas imagines mundi con el objetivo de saber si se tratan de un común denominador para toda la sociedad que estudiamos o es sólo representación de una parte de la sociedad ${ }^{24}$. Se anima a explorar las objetivaciones para saber quiénes son sus autores y quiénes comparten esa visión de las cosas: ¿todas las clases sociales?, ¿todos los grupos de edades? Aquí se examina si hay algún componente genérico en las analogías o si se trata de construcciones o actividades intelectuales comunes a hombres y mujeres. Si el logos analógico es palabra masculina ${ }^{25} \mathrm{o}$ actividad humana agenérica. Es un punto común en la reflexión teórica sobre la analogía en general que su razón de ser es colonizar lo desconocido a partir de algo conocido con lo que guarda una relación de similitud en al-

es desnaturalizar el pensamiento utilitario, considerarlo como otro universo simbólico más, llevarlo al terreno de la cultura. Así, la peculiaridad de la sociedad occidental es la preeminencia del «simbolismo económico», práctico o utilitario, que es «estructuralmente determinante». Pero este reconocimiento no dice nada sobre una hipotética simultaneidad de los tipos de pensamiento. Seguimos concibiendo dos universos distintos, si bien ambos simbólicos, si bien ambos en el ámbito de la cultura. Pero unas lógicas simbólicas dominan puntualmente a las otras. Y, a la vez, no pueden vivir sin las otras.

${ }^{24}$ «Hay que ir así del ergon a la energeia, siguiendo la oposición de Wilhem von Humboldt, de los objetos o de las conductas al principio de su producción o, más precisamente, de la analogía o de la metáfora efectuada, hecho realizado y letra muerta (a:b::::c:d), que considera la hermeneútica objetivista, a la práctica analógica como transferencia de principios que el habitus opera sobre la base de equivalencias adquiridas facilitando la posibilidad de sustituir una reacción por otra, y permitiendo dominar por una especie de generalización práctica todos los problemas que, con la misma forma, pueden surgir en situaciones nuevas. Recuperar a través del mito como realidad constituida el acto mitopoiético como momento constituyente no es, como lo piensa el idealismo, buscar en la consciencia las categorías universales de lo que Cassirer llama una "subjetividad mitopoiética" o, en el lenguaje de Lévi-Strauss, "las estructuras fundamentales del espíritu humano" que gobernarían, independientemente de las condiciones sociales, todas las configuraciones empíricamente realizadas. Es reconstruir el sistema socialmente constituido de estructuras inseparablemente cognitivas y evaluativos que organiza la percepción del mundo y la acción en el mundo conforme a las estructuras objetivas de un estado determinado del mundo social» (Bourdieu, 1991: 158).

${ }^{25}$ Hasta llegar a considerarlo no letra muerta, ejercicio neutro del intelecto, sino, como dice Molina, «topo-poder», acción del lenguaje masculino sobre el mundo que refleja el «todo-poder» masculino, caracterizado «por la capacidad de que la voluntad de nombrar se haga realidad, de que el discurso sea creación, de que el verbo se haga carne, de que el deseo se traduzca en posesiones y en recursos, y de otro lado, por la capacidad de asignar espacios para todo lo existente, de imponer un orden por el procedimiento de constreñir los lugares para cada criatura, de señalar a cada cosa «su sitio» (mientras Él puede estar en todos lo sitios y en todos los centros)» (2003: 143).

EMPIRIA. Revista de Metodología de Ciencias Sociales. N. ${ }^{0}$ 14, julio-dicembre, 2007, pp. 109-136. ISSN: $1139-5737$ 
guna de sus partes. Aquí se busca además la identidad de género del sujeto colonizador que pone en marcha ese complejo analógico.

En torno a la vaca se pueden identificar tres formas de analogía; las tres sitúan a elementos que pertenecen a órdenes diferentes (uno de los cuales es siempre la vaca) en relación homóloga.

Una de estas tres formas une a la vaca con el entorno mediante un juego que parece exclusivamente intelectual, casi poético. Como cuando se dice de una vaca que tiene «buena meseta» si presenta la enhuesadura del espinazo plana, situando en un mismo plano el lomo del animal y un accidente geográfico. $\mathrm{O}$ cuando se dice al ver una sierra que sólo presenta nieve a lo largo de su cumbre alargada: «parece una vaca estordegá» ${ }^{26}$. En este caso, la técnica analógica parece más un recurso poético que un intento de explicar un fenómeno climatológico, pues asimilarlo a la pintura de una vaca no lo explica, sino, como mucho, lo cubre de sentido. La analogía, aquí, ni trata de establecer leyes ni construye argumentación alguna, sino que establece similitudes estéticas. La analogía no es, en este caso, una técnica de persuasión o demostración más o menos exitosa ${ }^{27}$; no pretende captar la naturaleza de las cosas ni comprender una a partir de otra; el análisis de su densidad no resiste un envite. Es pura poiesis.

Sin embargo, puede considerarse poiesis masculina si el libre ejercicio del intelecto se ejecuta en un ámbito reservado al mundo masculino, como el ambito de las vacas. La actividad ganadera es, en términos genéricos, una actividad masculina en lo público y una actividad tanto masculina como femenina en lo privado. El trabajo en la recolección de la hierba que alimenta a las vacas, su alimentación diaria y la limpieza de los utensilios e instalaciones ganaderas es labor de ambos, pero la identidad vaquera es masculina, la venta de las vacas en el espacio de la producción - ferias y mercados- es masculina y entre los hombres el discurso sobre las vacas es constante y representa un porcentaje muy importante de su producción lingüística. Si concordamos que el mundo vacuno es un espacio simbólico de los hombres podremos concluir que, efectivamente, este recurso analógico es palabra masculina y no función humana cristalina. Visto así, la palabra masculina (el ejercicio analógico en este caso) es inclusiva para la sociedad de los hombres para la que crea un espacio de creatividad a partir de una actividad, la vaquera, en la que él es cabeza visible, mientras que a su vez, es excluyente para las mujeres que, en el mundo vaquero pasiego, ocupa un lugar oculto o, en cualquier caso, de nula proyección pública.

${ }^{26}$ Se les llama «estordegás» a vacas con una distribución peculiar del color: sus costados son negros o marrones excepto a lo largo de todo el espinazo que es blanco.

${ }^{27}$ Como sucedía con las primitivas formas de argumentación analógica de los griegos (Lloyd, 1987). Con ellas, esta variedad del pensamiento analógico pasiego guarda, si acaso, cierta similitud en su escasa consistencia estructural: la analogía es débil y no resiste un examen de concordancias exhaustivo. Pero la diferencia es enorme, pues para los filósofos y tratadistas griegos la analogía era «método» orientado a un fin de tipo demostrativo y para los pasiegos esta modalidad de analogía es «herramienta» orientada a un fin de carácter expresivo. 
La forma y estructura de las analogías que se mencionan en lo que sigue son diferentes de las que caracterizan la analogía revisada más arriba. Y, pese a que se ha concluido que el mundo de las vacas es masculino y que cualquier recurso relacionado con las vacas ha de ser tomado como producción intelectual exclusiva de la sociedad de los hombres estas nuevas formas del pensamiento y de la práctica analógica serán examinadas a continuación buscando nuevas maneras de producir masculinidad.

La segunda de las formas analógicas une a la vaca con las personas en general, sin distinción de géneros como cuando se dice que una vaca es maja «lo mismo que una persona que es maja», pero puede incluir una acción práctica que sitúa en un plano análogo a vacas y personas por igual como cuando se les cortan los pelos del rabo a las vacas con la tijera antes de llevarlas a la feria y se justifica diciendo «tú vas bien afeitao y bien trajeao (y) paeces bien». La tercera de las formas analógicas que unen a la vaca con el entorno sitúa al animal en un plano similar al de la mujer, tanto desde la perspectiva del lenguaje como desde una perspectiva práctica. Desde el plano del lenguaje, son muchas las expresiones que sitúan a la vaca como a la mujer, como cuando se dice que la cabeza bonita de una vaca es «como la mujer si es guapa»; y, también, son muchas las acciones que se llevan a cabo sobre la vaca como si de una mujer se tratara. Sobre todo durante el parto de la vaca cuando se la recluye en la casa (cuadra) y se la somete a un régimen homólogo al de la mujer que pare.

Y, especialmente, cuando se acude con la vaca a la feria, momento en el que la vaca es llevada simbólicamente a una boda (con el tratante) y, por ello, se la arregla y presenta en las mejores condiciones (se le corta el pelo, a veces se le lava con champú, se le puede dar colorante en el ubre para encarnarlo, se depila el ubre, se tapan defectos con betún a modo de maquillaje... acciones que no se llevan a cabo siempre ni por todos los ganaderos, pero que forman parte del repertorio cultural de arreglos analógicos de las vacas).

La analogía que homologa la vaca en la feria con una mujer el día de la boda objetualiza a la mujer trasladándola simbólicamente al mundo de las transacciones masculinas. La lectura de la analogía nos dice que el ganadero busca comprador (tratante) para su mercancía (la vaca), de manera análoga a como se busca un novio para una chica. Para conseguirlo se prepara a la vaca para un encuentro importante como si de una mujer se tratara ante un encuentro similar.

Esta manera analógica que tienen los hombres de proceder con las vacas en las ferias tiene una historia reciente en la pasieguería. Es una analogía nueva, que podría ilustrar el surgimiento del pensamiento analógico a partir de la introducción de la raza holstein tras un proceso de racionalización, tal y como se hizo con otros ejemplos en el apartado anterior. Antes de la introducción de la frisona no existía la venta en un recinto público de una vaca recién parida para ser explotada por terceros. Y la venta masiva de estas vacas lecheras en espacios públicos irá en aumento desde su introducción, lo que corrobora lo novedoso del complejo analógico. El camino que lleva a las vacas frisonas a llenar los recintos feriales comienza a finales del XIX, pero es en la segunda mitad del siglo XX 
cuando alcanza sus índices más altos ${ }^{28}$. Antes de mediar el siglo XIX los pasiegos pastoreaban con una vaca diferente, cuyos productos, especialmente mantequillas y quesos, eran vendidos en ferias locales. Esta actividad se complementaba con otras fuera de los montes pasiegos, principalmente el comercio de telas, tabacos o productos de contrabando. También recibieron ingresos los grupos domésticos en los que alguna mujer alquilaba sus servicios como nodrizas, generando lo que se ha dado en llamar «parentesco de leche». Este panorama descrito en unas pocas líneas tenía a hombres y a mujeres mercadeando constantemente por buena parte de la geografía peninsular en una especie de nomadeo hacia fuera tanto o más salvaje que el nomadeo intensivo que se empezó a gestar a finales del XIX con la introducción de la vaca frisona ${ }^{29}$.

«El pasiego fue, como vimos, originariamente pastor, y el pastoreo es su más entrañable vocación, aunque no la única, pues en determinadas circunstancias el pasiego ha sido y sigue siendo un pueblo de raras aptitudes para la actividad comercial. Muchos pasiegos fueron en otros tiempos traficantes, buhoneros y contrabandistas. Una explotación insuficiente de los recursos del suelo le obligaron en los Montes de Pas a la emigración y al ejercicio de actividades auxiliares y complementarias a la ganadería. El contrabando fue estimulado por la proximidad a las tierras del señorío de Vizcaya y como consecuencia de los privilegios concedidos por Felipe IV a los puertos vizcainos de una rebaja de un 5\% en la importación, así como al desestanco del tabaco en las provincias vascas y la situación privilegiada del comercio en éstas en virtud de los fueros. Tradicional es también el comercio ambulante. La vida del pasiego empieza con gran frecuencia comerciando en quesos o clavos y la de la pasiega como vendedora de cintas, telas y baratijas. (...) El contrabando,

28 «Hasta 1853 , en que se concede a los ayuntamientos facultad para crear sus propias ferias y mercados, no existían más que ferias anuales de ganado en distintos puntos de la provincia, algunos mercados semanales en los que se vendían toda clase de géneros, y entre ellos también ganado, y muy pocos mercados periódicos exclusivamente ganaderos. (...) desde mediados del siglo XIX y como consecuencia del crecimiento experimentado por la demanda de ganado para carne, el número de ferias y la multiplicación de los lugares de contratación fue creciendo en la provincia, pasando de 27 en 1859 a 80 en 1892. pero la mayor parte de las nuevas ferias eran de carácter anual; sólo nueve, a finales de siglo, tenían una convocatoria mensual, y únicamente Torrelavega mantenía una feria quincenal» (De la Puente 1995: 200-201). A medida de que se cierra el siglo XIX la orientación cárnica de los mercados ha ido dejando paso a la lechera raza holstein del tronco frisón que, poco a poco, excepto en algunos períodos puntuales, va llenando los mercados más prósperos hasta convertirse en mayoritaria en amplias zonas de la región y, por supuesto, en territorio pasiego.

${ }^{29}$ Que los pasiegos tenían una gran movilidad fuera de su territorio y que ello era conocido en el resto de la región dan una idea las ordenanzas concejiles de la localidad de Polientes del año 1891, localidad situada a unos 50 kilómetros de la localidad pasiega más cercana. En el artículo 1, «Del modo de convocar a concejo y puntual asistencia y multa en que incurre el contraventor» se dice: «(...) Si dado el previo aviso o tocando dos veces la campana, según los casos, algún vecino se ausentase, pagará cincuenta céntimos de peseta por vía de multa siempre que su ausencia no sea motivada por orden superior o necesidad forzosa, cual sucede a médicos, cirujanos, farmacéuticos y cualquier otro vecino que tenga costumbre de hacer viajes, como los pasiegos, etcétera» (Baró, J., y Pérez, R., 1991: 228).

EMPIRIA. Revista de Metodología de Ciencias Sociales. N. ${ }^{\circ}$ 14, julio-dicembre, 2007, pp. 109-136. ISSN: 1139-5737 
desaparecido al mediar el siglo XIX, y el comercio, fueron siempre actividades secundarias, en retroceso conforme el pasiego se habituaba a una vida de ganadería (...)» (De Terán, op. cit., pp. 519-521).

Tan interesante como lo novedoso del pensamiento analógico sobre la venta de vacas es el hecho de que esta práctica analógica coincida con un proceso creciente de recogimiento de hombres y mujeres en las montañas pasiegas. La estructura social emergente desde finales del XIX se caracteriza por el nuevo papel de la mujer recluida en territorio pasiego y en territorio doméstico (que choca con la mujer comerciante y trajinadora de períodos anteriores), y el nuevo papel del hombre al mando de una ganadería creciente (que rompe con una actividad hasta entonces comerciante y buhonera como complemento a un pastoreo mucho menos intenso que el que se empieza gestar en esas fechas). Procesos ambos que progresan con el paso de los años. A medida que la mujer va perdiendo su actividad económica externa va creciendo el complejo analógico que, dentro del universo que está emergiendo, la sitúa simbólicamente en el intercambio de mercancías masculino que tiene lugar en las ferias. Hasta el último cuarto del siglo XIX la mujer tuvo, posiblemente, un papel más destacado en el universo pasiego que el que habría de tener en el siglo XX, tanto por lo que dicen las nuevas analogías como por la constatación de los nuevos roles que empiezan a desempeñar. Los pasiegos entraron, a partir de esa fecha, en una nueva fase de su historia.

Por lo tanto, las prácticas que sitúan a las vacas y a las personas en un mismo plano o las que sitúan a vacas y mujeres en situación homóloga pueden entenderse como una práctica masculina (por mucho que las mujeres participen de ellas), más claro en el caso de la analogía vaca/mujer, instaurada progresivamente desde la adquisición de la vaca frisona a finales del XIX y como forma de dar sentido mediante esas prácticas descritas a un animal que estaba siendo incorporado al universo pasiego y que por analogía se trata de la misma manera que lo que se tiene alrededor, sea hombre, mujer o ambos.

No son las únicas expresiones del pensamiento salvaje que tienen una lectura en estos términos. Las metáforas del coito que esgrimen los hombres pasiegos se muestran aún más transparentes a la hora de escrutar las bases sociales de su producción. En ellas suelen aparecer representados tanto el hombre como la mujer, mediante un discurso jerarquizado en donde la mujer ocupa plaza de segundo orden (debajo y pasiva) mientras el hombre ocupa plaza principal (arriba y activa). Metáforas como «echar majuelo al campano» o «belortear» no son letra muerta, ejercicios retóricos puros, limpios de condición social alguna; son, al contrario, palabra masculina. Son los hombres los que juegan con las metáforas cuando hablan entre ellos, y son los hombres los que mediante este simple ejercicio intelectual envían a las mujeres a ocupar una plaza de segundo orden en el universo local. También la metáfora salvaje puede ser escrutada en sus orígenes sociales; más complicado es, de momento, rastrear en su historia. 


\section{BIBLIOGRAFÍA}

ARCHE, F. (1945): El ganado vacuno en la montaña. Talleres tipográficos del hogar provincial de Santander.

BARó, J., y PÉrEZ, R. (1991): El gobierno y la administración de los pueblos de Cantabria. II, Valle de Valderredible. Diputación Regional de Cantabria.

BouRdieu, P. (1991): El sentido práctico. Taurus.

Bouveresse, J. (2001): Prodigios y vértigos de la analogía. Sobre el abuso de la literatura en el pensamiento. Libros del Zorzal.

CÁTEDRA, M. (1989): «Las vacas también son buenas para pensar», La vida y el mundo de los vaqueiros de alzada (Cátedra, M.), pp. 129-165. CIS.

- (1979): «Vacas y vaqueiros. Modos de vida y cultura en las brañas asturianas», en Vaqueiros y pescadores. Dos modos de vida (Cátedra, M., y Sanmartín, R.), pp. 13-93. Akal.

ClifFord, J. (1999): Itinerarios transculturales. Gedisa.

De la CAlle, J. (1999): Mudando la vida. Vida cotidiana y maneras de pensar en la pasieguería a finales del siglo XX. Tesis Doctoral. UNED.

De LA PuENTE, L. (1995): «El papel histórico de Torrelavega en la organización del espacio ganadero: los mercados de ganado bovino, 1844-1994», en Torrelavega. Tres siglos de historia (Sánchez, M.A., ed.). Universidad de Cantabria y Ayuntamiento de Torrelavega.

De TeráN, M. (1947): «Vaqueros y cabañas en los Montes de Pas», en Estudios Geográficos n. ${ }^{\circ}$ 28, pp. 493-536. Publicaciones del Instituto «Juan Sebastián Elcano».

DetienNe, M. y Vernant, J. P. (1988) (or.1974): Las artimañas de la inteligencia. La metis en la Grecia antigua. Taurus.

Douglas, M. (2006): El Levítico como literatura. Gedisa.

- (1975): Sobre la naturaleza de las cosas. Cuadernos Anagrama.

GARCÍA-Allut, A. (2003): «O Prestige: Teoría social da catástrofe»; apdo 2: «O Prestige e as comunidades pesqueiras», en ¿Qué foi do Prestige?, (Cabrera, J. Y García-Allut, A. coords.), pp. 102-124. Sotelo Blanco.

Goody, J. (1985) [1977]: La domesticación del pensamiento salvaje. Akal.

- (1982) [1970]: «Comprensión y explicación en sociología y antropología social», en La explicación en las ciencias de la conducta (VVAA), pp. 159-207. Alianza Editorial.

LÉVI-STRAUSS, C. (2005) [1962]: El pensamiento salvaje. FCE.

- 1990 [1978]: Mito y significado. Alianza Editorial.

LizCANO, E. (2006): «Sacralidad de la ciencia y metáforas de pureza», en Metáforas que nos piensan. Sobre ciencia, democracia y otras poderosas ficciones (Lizcano, E.), pp. 239246. Ediciones Bajo Cero.

Lloyd, G. E. R. (1987): Polaridad y analogía. Dos tipos de argumentación en los albores del pensamiento griego. Taurus.

LÓPEZ, A. (1888): «Disertación sobre la manera de fomentar los principales elementos de riqueza de la provincia de Santander», en Juegos Florales, pp. 133-178 (ejemplar fotocopiado).

Madariaga, B. (1970): «La ganadería en la provincia de Santander», en Publicaciones del Instituto de Etnografía y Folklore 'Hoyos Sainz'. Vol. II. Diputación Provincial de Santander.

MolinA, C. (2003): «Género y poder desde sus metáforas. Apuntes para una topografía del patriarcado», en Del sexo al 'género'. Los equívocos de un concepto Tubert, S., ed., pp. 123159. Cátedra.

EMPIRIA. Revista de Metodología de Ciencias Sociales. N. ${ }^{\circ}$ 14, julio-dicembre, 2007, pp. 109-136. ISSN: $1139-5737$ 
Morin, E. (2004): «Mente y conciencia», en La identidad humana. El método V, pp. 105-126. Círculo de Lectores.

NiETo, J. A. (2003): «Reflexiones en torno al resurgir de la Antropología de la Sexualidad», en Antropología de la Sexualidad y diversidad cultural (Nieto. J. A., ed.), pp. 15-51. Talasa.

- (1989): Cultura y sociedad en las prácticas sexuales. FUE.

ORTEGA, J. (1975): «Organización del espacio y evolución técnica en los Montes de Pas», en Estudios Geográficos, 36 (140-141), pp. 863-899.

SAHLINs, M. (2006) [1976]: Cultura y razón práctica. Contra el utilitarismo en la teoría antropológica. Gedisa.

TAX DE FreEMAN, S. (1986): «Los pasiegos», en AIC, n. ${ }^{\circ}$ 26, pp. 31-38.

WINCH, P. (1994): Comprender una sociedad primitiva. Paidós. 


\section{RESUMEN}

Durante mucho tiempo la antropología ha caracterizado a las sociedades primitivas como sociedades de pensamiento mitopoiético, en las antípodas de aquellas sociedades en las que gobierna el pensamiento racional al servicio de la rentabilidad, el rendimiento y la productividad. Hecho de metáforas, analogías y otras herramientas del intelecto, el mito, como forma discursiva, identificaba y representaba a la sociedad primitiva entera. El mito era el pensamiento salvaje.

Lo dicho para las sociedades primitivas vale para las sociedades tradicionales en las que encontramos prácticas y discursos mitopoiéticos, como en el ejemplo que se analiza en estas páginas: la analogía salvaje de los pasiegos en torno al ganado vacuno.

Avanzando y rastreando la analogía salvaje, se plantean dos cuestiones sobre el pensamiento analógico de los pasiegos: la primera de ellas, el papel de la analogía en el origen de la cultura y del cambio cultural y, la segunda, su género, de manera que podamos afirmar que el universo analógico de los pasiegos es fundamentalmente masculino, femenino o ejercicio agenérico del intelecto humano.

Se trata de reflexionar sobre qué de salvaje tiene el pensamiento salvaje - entendiendo salvaje como un pensamiento humano prístino-: por un lado en sus relaciones con el racionalismo (¿emerge la analogía desde el racionalismo?, ¿qué relación guarda con éste?, ¿su nacimiento es resultado de una función «natural»?) y por otro sobre la naturaleza social de lo salvaje a partir de las bases sociales que lo producen. Es decir, se rastrea lo que de salvaje tiene la analogía, si la analogía es o no una función ahistórica y asocial del intelecto humano.

No se examina todo el complejo analógico de los pasiegos, únicamente aquél que establece relaciones homólogas entre las vacas y el entorno.

\section{PALABRAS CLAVE}

Pensamiento salvaje, pensamiento analógico, pensamiento racionalista, racionalismo y productividad.

\section{ABSTRACT}

During long time anthropology has defined primitive societies as societies of mythopoietical thought. Just the opposite of those societies in which it governs the rational thought to the service of profitability and productivity. Myth constructs its discursive form with metaphors, analogies and other tools of the intellect. It represents and identifies the primitive society as a whole. Myth was the wild thought.

This idea could also be applied to traditional societies. In these societies we found mythopoietical praxis and speeches, like in the example that is analyzed in this paper: the wild analogy of pasiegos in relationship with their cattle. 
We have to consider two questions on the analogical thought of pasiegos. First, the role of analogy in the origin of the culture and the dynamic of cultural change. Second, gender analogy: is the analogical universe of pasiegos masculine, feminine, or without gender?

Additionally, under the consideration that «wild» is a pristine human thought, we ask ourselves how much of wild has the wild thought,. First at all in its relation with rationalism: emerges analogy from rationalism? What relation analogy maintains with rationalism? Its origin is the result of a «natural» function? By the same token, we ask on the social nature of the savage. That is to say, how much of wild has the analogy. Whether or not the analogy is an ahistorical and asocial function of human intellect.

One final observation: All the analogical complex of pasiegos is not examined. We only analizes that one that establishes homologous relations between the cows and the habitat.

\section{KEY WORDS}

Wild Thought, Analogical Thought, Rationalist Thought, Rationalism and Productivity. 